\title{
Kinetics of Intestinal Presence of Spores Following Oral Administration of Bacillus clausii Formulations: Three Single-Centre, Crossover, Randomised, Open-Label Studies
}

\author{
Pierluigi Navarra ${ }^{1} \cdot$ Stefano Milleri ${ }^{2} \cdot$ Marcos Perez $\mathrm{III}^{3} \cdot$ Maria Chiara Uboldi ${ }^{4} \cdot$ Paolo Pellegrino $^{4}$. \\ Beatrice Bois De Fer ${ }^{5}$ Lorenzo Morelli ${ }^{6}$
}

Received: 5 November 2020 / Accepted: 12 February 2021 / Published online: 8 March 2021

(c) The Author(s) 2021

\begin{abstract}
Background and Objective Probiotics are live microorganisms that may provide benefits including the prevention of gastrointestinal disorders and other diseases. Enterogermina is a probiotic mix of spores from four strains of Bacillus clausii $(\mathrm{O} / \mathrm{C}$, T, N/R and SIN), available in several oral formulations. The objective of this analysis was to evaluate and compare the kinetic profiles of different formulations of Enterogermina - vial [E4 once daily (OD) and E2 twice daily (BID)], capsule [EC2 three times daily (TID)], oral powder for suspension (ES6 OD) and oral powder not requiring suspension (E6 OD) from two studies from 2012 (EUDRACT 2010-024497-19 and 2010-023187-41) and one study from 2016 (EUDRACT 2015-003330-27).

Methods B. clausii spores were counted in homogenised faecal samples (results expressed as counts per gram) or after culture at $37^{\circ} \mathrm{C}$ for $24-36 \mathrm{~h}$ (results expressed as colony-forming units). Kinetics were assessed by area under the concentrationtime curve (AUC), maximum concentration $\left(C_{\max }\right)$, time to maximum concentration $\left(T_{\max }\right)$ and spore presence/persistence. Results In total, 22 subjects in each of the 2012 studies and 30 subjects in the 2016 study were randomised (mean age $25.0-33.8$ years across studies). The mean $( \pm \mathrm{SD})$ absolute faecal spore counts (in millions) expressed as AUC per hour were $270.7 \pm 147.7$ (E2 BID) and 213.8 $\pm 60.2(\mathrm{E} 4 \mathrm{OD})$ in 2012 EGKINETIC4, $312.7 \pm 218.0$ (EC2 TID) and $319.0 \pm 221.1$ (ES6 OD) in 2012 EGKINETIC6, and 212.6 \pm 118.0 (E6 OD) and 293.2 \pm 247.2 (ES6 OD) in 2016 EGKINETIC6OP. The kinetic profiles of the different formulations of Enterogermina were similar, with superimposable AUC and daily curve profiles in each study up to the 8th day post dose. B. clausii spore presence/persistence in the intestine of healthy volunteers did not differ between the two formulations within each of the three studies. Enterogermina was well tolerated across all formulations and studies.

Conclusion These results show different formulations of Enterogermina had similar kinetic profiles within each study; however, they also showed that probiotics could be associated with high variability. The European Medicines Agency guidelines are the current bioequivalence reference, although only the $T_{\max }$ parameter is used for high variability drugs. Due to the specific kinetics of probiotics, new parameters of bioequivalence could be necessary, considering, for example, variability via a parameter such as AUC.
\end{abstract}

Trial registration EUDRACT 2010-024497-19, 2010-023187-41 and 2015-003330-27.

Maria Chiara Uboldi

MariaChiara.Uboldi@sanofi.com

Extended author information available on the last page of the article 


\section{Key points}

Different formulations of Enterogermina show potential bioequivalence.

Probiotics can be associated with high kinetic variability.

New parameters could be considered for probiotic specific bioequivalence guidelines.

\section{Introduction}

Probiotics are live microorganisms that provide potential health benefits including the prevention of various gastrointestinal disorders and other diseases [1,2]. The oral administration of probiotics has been shown to improve the balance between intestinal permeability and epithelial barrier function as well as having a direct positive effect on metabolic syndrome, atherosclerosis, inflammatory bowel diseases and colon cancer [3].

Enterogermina is an oral probiotic product consisting of spores from 4 strains of Bacillus clausii $(\mathrm{O} / \mathrm{C}, \mathrm{T}, \mathrm{N} / \mathrm{R}$ and SIN), available in a range of oral formulations. B. clausii is a non-pathogenic alkali-tolerant spore-forming aerobic, facultative anaerobic Gram-positive strain of bacteria [4, 5] that can survive transit through the acidic environment of the stomach and colonise the intestine even in the presence of antibiotics [6-8]. Enterogermina has been shown to reduce the duration of acute diarrhoea in children older than 6 months [9] and to reduce the incidence of abdominal pain and diarrhoea associated with antibiotic treatment in patients of all ages when taken during antibiotic treatment and for the following 7-10 days [9]. Enterogermina re-establishes the balance of resident flora and can consequently be used for the treatment and prevention of intestinal dysbiosis as seen during treatment with antibiotics or chemotherapy, or in patients with endogenous avitaminosis [9].

Enterogermina has been widely used in Italy since the 1960s for diarrhoea in children and for managing the sideeffects of antibiotics [10-13]. Recently developed once-daily formulations may offer a suitable alternative to the three times daily dosage, potentially leading to better compliance and adherence to therapy [14].

When probiotics such as Enterogermina are intended for use as a drug, they must undergo the same regulatory process and analyses. However, probiotics are inherently different to drugs in that they are dynamic living organisms. Current parameters for the kinetic analysis of drugs such as absorption and release may therefore need to be re-assessed and considered within the context of probiotic analysis.

Our objective was to summarise the kinetic profiles of different formulations of Enterogermina (vial, capsule, oral powder for suspension and oral powder with no need for suspension), from three studies undertaken between 2012 and 2016 (EUDRACT 2010-024497-19, 2010-023187-41 and 2015-003330-27), which measured the concentration of colony-forming units (CFUs) of spores/vegetative forms as kinetic parameters as well as the measurement of area under the concentration-time curve (AUC), maximum concentration $\left(C_{\max }\right)$ and time to maximum concentration $\left(T_{\max }\right)$ in faecal samples.

\section{Methods}

\subsection{Participants}

All studies enrolled male and female Caucasian healthy volunteers aged between 18 and 45 years, with a body mass index between 19 and $28 \mathrm{~kg} / \mathrm{m}^{2}$, regular bowel movements (daily evacuation), and blood pressure, heart rate and laboratory parameters within normal limits. Volunteers were also required to have a negative pregnancy test and to use highly effective contraceptive methods (females).

Volunteers were excluded if they had experienced previous serious gastrointestinal disease, or if they had received antibiotics, probiotics, antacids, proton pump inhibitors or prokinetics 2 months prior to the first dose. They were also required to have no allergies to foodstuffs or drugs, not to be vegetarian, and not to have an abnormal diet of $<1600$ Kcal per day or $>3500 \mathrm{Kcal}$ per day. Volunteers were also excluded if they had a history of alcohol or drug abuse, smoked $>10$ cigarettes per day, had previous serious metabolic, hepatic, renal, pulmonary, or cardiovascular disease or any history of epilepsy, asthma, diabetes, psychosis or glaucoma. They must not have received pharmacological treatment two weeks prior to the first dose (excluding NSAIDs/ oral contraceptives), and must not have tested positive for HIV and/or hepatitis B or C.

\subsection{Study Design}

Three single-centre, comparative, randomised, open-label crossover studies were conducted in Italy (see Table 1 for Enterogermina formulation, spore concentration and dose regimen). Each formulation contains all four $B$. clausii strains $(\mathrm{O} / \mathrm{C}, \mathrm{T}, \mathrm{N} / \mathrm{R}$ and $\mathrm{SIN})$ at the same relative concentration.

All studies followed the same design (Fig. 1). Eligible subjects entered a screening phase performed within 21 days of the first dose. During the last week preceding treatment 
Table 1 Enterogermina formulation, spore concentration and dose regimen

\begin{tabular}{|c|c|c|c|c|c|}
\hline Study name & Test or reference & Oral formulation & $\begin{array}{l}\text { Spore concen- } \\
\text { tration }\end{array}$ & Dose regimen & Name \\
\hline \multirow{2}{*}{$\begin{array}{l}2012 \text { EGKINETIC4 } \\
\text { (EUDRACT 2010-023187-41) }\end{array}$} & Test & Vial & $4 \times 10^{9}$ & OD & E4 OD \\
\hline & Reference & Vial & $2 \times 10^{9}$ & BID & E2 BID \\
\hline \multirow{2}{*}{$\begin{array}{l}2012 \text { EGKINETIC6 } \\
\text { (EUDRACT 2010-024497-19) }\end{array}$} & Test & Powder for suspension & $6 \times 10^{9}$ & OD & ES6 OD \\
\hline & Reference & Capsule & $2 \times 10^{9}$ & TID & EC2 TID \\
\hline \multirow{2}{*}{$\begin{array}{l}\text { 2016 EGKINETIC6OP } \\
\text { (EUDRACT 2015-003330-27) }\end{array}$} & Test & Powder (no suspension) & $6 \times 10^{9}$ & OD & E6 OD \\
\hline & Reference & Powder for suspension & $6 \times 10^{9}$ & OD & ES6 OD \\
\hline
\end{tabular}

$B I D$ twice daily, $O D$ once daily, $T I D$ three times daily

and for the two study periods, subjects were asked to complete a daily run-in diary in which they reported the number and time of evacuations and faecal consistency (hard, formed/hard, formed/normal, formed/soft; soft, watery, overt diarrhoea).

Test and reference products were administered under fasting conditions on the assumption that fasting provides the most sensitive environment in which to detect a potential difference between formulations. In the first period each subject received the selected formulation of Enterogermina (assigned according to the randomisation list). The first dose of treatment was given before breakfast after fasting from midnight for all formulations (OD, BID and TID). The second dose was administered before lunch after fasting for at least $4 \mathrm{~h}$ for BID and TID regimen; the third dose (only applicable for TID regimen) was administered before dinner after fasting for at least $4 \mathrm{~h}$.

The protocols of the three studies complied with recommendations of the 18th World Health Congress (Helsinki, 1964) and all applicable amendments. The protocols also complied with the laws and regulations, as well as any applicable guidelines from the country where the study was conducted. Informed consent was obtained prior to the conduct of any study-related procedures.

\subsection{Measurements and Timing}

Before the supplementation of Enterogermina, the faeces (single faecal sample) of the subjects were analysed at T0 (time zero) to evaluate the presence of spores and vegetative cells of B. clausii. After the administration of Enterogermina, the faeces of the volunteers were analysed for the presence of spores and vegetative cells (2012 studies only) of $B$. clausii. The subjects collected faeces daily in suitable containers and delivered them to the study centre. The samples were then sent daily (refrigerated but not frozen) to the central laboratory by $2.30 \mathrm{pm}$. The first evacuation of the day was considered for analysis for the 2012 studies; however, for the 2016 study, samples from all evacuations in the first 3 days were collected and evaluated.
In order to ensure comparability of faecal microbiota within subjects between crossover periods, the pre-dose stool samples were matched by polymerase chain reaction denaturing gradient gel electrophoresis (PCR-DGGE) as previously described $[15,16]$.

In the first and second study period, subjects were followed up to disappearance of B. clausii from faeces for a maximum period of 18 days, with a wash-out period of at least 7 days in between $[17,18]$. A visit took place within 7-14 days of the end of the second study period. For each subject, the study period was stopped early if the daily collection of stools (first evacuation) showed an absence of spores or vegetative forms (spores only in the 2016 study).

\subsection{Objectives}

The primary objective of each of the studies was to describe the kinetic profile of bacterial growth of different formulation and dose regimens of Enterogermina. The secondary objectives were to evaluate the presence/persistence of $B$. clausii spores in the intestine by bacterial count [spores and vegetative forms (2012 studies only)] in faecal recovery of the two formulations and to evaluate the safety of each formulation and dose regimen.

\subsection{Kinetic Variables}

\subsubsection{Spore and Vegetative Cell Counts}

A faecal sample $(1 \mathrm{~g})$ was homogenised in sterile saline $(9 \mathrm{~g}$ $\mathrm{NaCl} / \mathrm{L})(1: 10)$ and further serial dilutions were performed. An appropriate decimal dilution was plated on a blood agar base (Oxoid) with $100 \mu \mathrm{g} / \mathrm{mL}$ of erythromycin and the plates were incubated in aerobic conditions at $37^{\circ} \mathrm{C}$ for $24-36 \mathrm{~h}$ in order to select for $B$. clausii vegetative (total) cells [7, 17]. The presence of $B$. clausii spores in faeces was counted by the same method after heat shock treatment of the dilutions. The results were expressed as CFUs of vegetative cells and spores of B. clausii per gram of wet stool. After the count of spores and vegetative forms, the faecal samples were stored 
at $-20{ }^{\circ} \mathrm{C}$ for other potential analysis on intestinal microbiota (non-genomic assessment) that can be performed within two years. The AUC and presence/persistence rates were calculated for both counts; $\mathrm{T}_{\max }$ and $\mathrm{C}_{\max }$ were calculated only for the 2016 study (EGKINETIC6OP).

\subsection{Treatment-Emergent Adverse Events (TEAEs)}

TEAEs were assigned to a preferred term and were classified by primary System Organ Class (SOC) according to the Medical Dictionary for Regulatory Activities (MedDRA). Laboratory and vital signs data were presented as summary statistics of values at each visit and changes from screening.

\subsection{Statistical Methods}

Sample sizes were not calculated on a statistical basis due to the explorative nature of the study. No inferential analyses were performed on primary and secondary endpoints and treatment groups were compared descriptively and graphically. Pre-dose stool samples were matched by means of a similarity coefficient (\%) from the PCR-DGGE analysis without differentiation. Similarity was considered maintained if $80-100 \%$; lower results were taken to indicate an impairment of the microbiota. The Dice algorithm was used as the reference. The concentration of CFUs for spores/ vegetative forms was used to determine kinetic parameters, and group-based and subject-based CFU curves were also graphically compared after log transformation. $\mathrm{AUC}_{0-t}$ (area under the curve from the time of treatment up to the total absence of measurable quantities) was calculated per hour and expressed in millions for the absolute values using the trapezoidal method based on the concentration of CFUs. The results of median time of presence/persistence for spores and vegetative forms were presented in the form of curves calculated using the Kaplan-Meier method and compared graphically. A post hoc analysis estimated standard deviation (SD) and coefficient of variation within each study.

\section{Results}

\subsection{Subjects}

A similar number of subjects was enrolled in each study (EGKINETIC4, $n=32$; EGKINETIC6, $n=27$; EGKINETIC6OP, $n=39$ ). Five subjects failed the screen in 2012 EGKINETIC4, nine in EGKINETIC6 and 10 in EGKINETIC6OP. In total, 22 subjects in each of the 2012 studies and 30 subjects in the 2016 study were randomised. In each study, equal numbers of subjects were allocated to the treatment sequence Test $\rightarrow$ Reference $(\mathrm{T} \rightarrow \mathrm{R})$ or Reference $\rightarrow$ Test $(\mathrm{R} \rightarrow \mathrm{T})$. One subject dropped out from each of the 2012 EGKINETIC4 and 2016 EGKINETIC6OP studies (see Fig. 2 for flow diagram).

The mean participant age was similar in both arms for all 3 studies with the highest disparity in 2012 EGKINETIC 4 where subjects had a mean age of 25 years (SD 2.9) in the

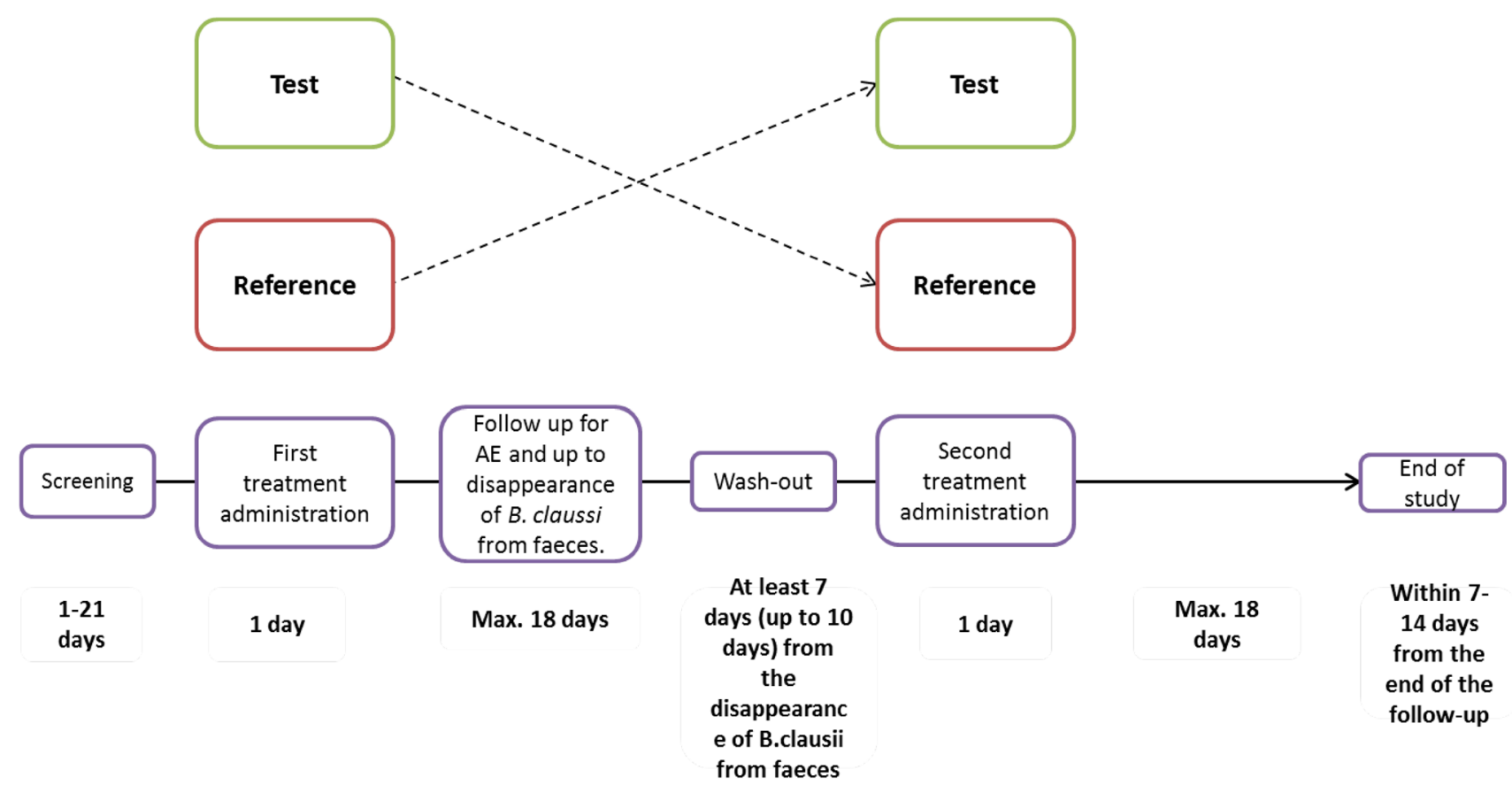

Fig. 1 Study design was the same for all three studies. $A E$ adverse event 


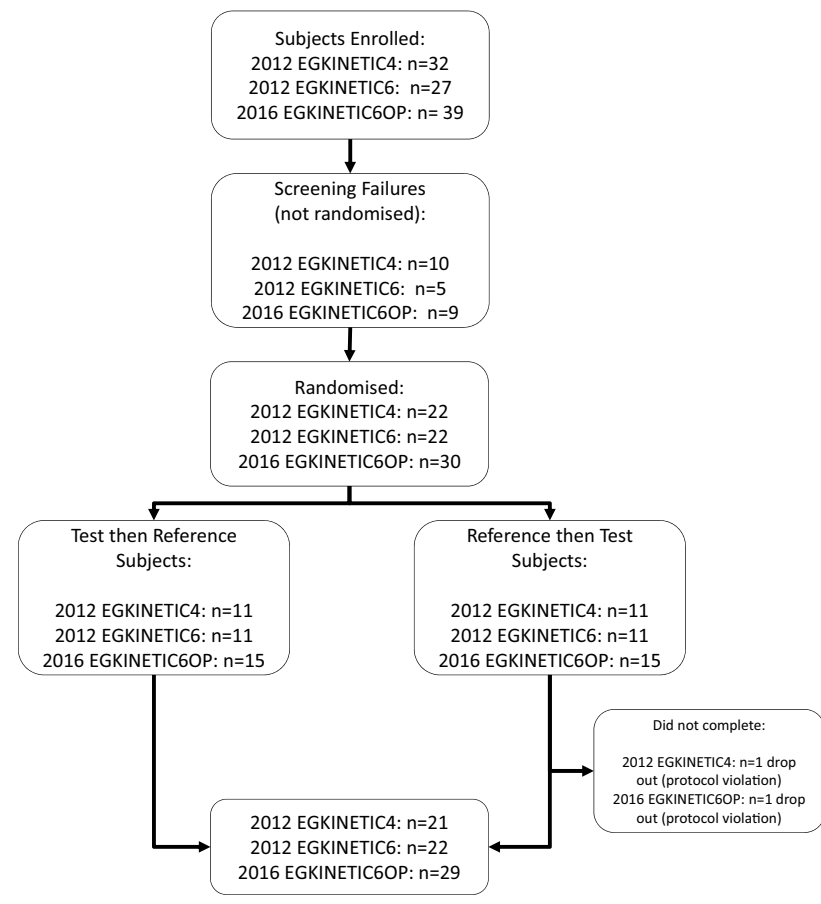

Fig. 2 Subject flow
E2 BID-E4 OD arm and 33.8 (SD 6.2) in the E4 OD-E2 BID arm. The mean age of the subjects in the other studies fell within this range. Slightly more males than females were enrolled across all studies (Table 2).

\subsection{Analysis of AUC/Spore Count}

\subsubsection{EGKINETIC4}

The mean $( \pm \mathrm{SD})$ absolute spore count (in millions) expressed as AUC per hour was $270.7 \pm 147.7$ with E2 BID and $213.8 \pm 60.2$ with E4 OD (Table 3). The AUC mean after logarithmic transformation is presented in Fig. 3a. The mean $( \pm \mathrm{SD})$ absolute vegetative (total) forms count (in millions) expressed as AUC was $273.7 \pm 155.7$ with E2 BID and $239.0 \pm 95.0$ with E4 OD.

\subsubsection{EGKINETIC6}

The mean $( \pm \mathrm{SD})$ absolute spore count (in millions) expressed as AUC per hour was $312.7 \pm 218.0$ with EC2 TID and $319.0 \pm 221.1$ with ES6 OD (Table 3). The AUC

Table 2 Baseline characteristics of study subjects

\begin{tabular}{|c|c|c|c|c|c|c|c|}
\hline \multirow{3}{*}{$\begin{array}{l}\text { Character- } \\
\text { istic }\end{array}$} & & \multicolumn{2}{|c|}{2012 EGKINETIC4 $^{\mathrm{a}}$} & \multicolumn{2}{|c|}{2012 EGKINETIC6 $^{\mathrm{a}}$} & \multicolumn{2}{|c|}{2016 EGKINETIC6OP } \\
\hline & & $\mathrm{E} 2 \mathrm{BID} \rightarrow \mathrm{E} 4 \mathrm{OD}$ & $\mathrm{E} 4 \mathrm{OD} \rightarrow \mathrm{E} 2 \mathrm{BID}$ & $\begin{array}{l}\mathrm{EC} 2 \mathrm{TID} \rightarrow \mathrm{ES} 6 \\
\mathrm{OD}\end{array}$ & $\begin{array}{l}\text { ES6 OD } \rightarrow \text { EC2 } \\
\text { TID }\end{array}$ & $\mathrm{E} 6 \mathrm{OD} \rightarrow \mathrm{ES} 6 \mathrm{OD}$ & ES6 OD $\rightarrow$ E6 OD \\
\hline & & $(N=8)$ & $(N=10)$ & $(N=10)$ & $(N=11)$ & $(N=15)$ & $(N=15)$ \\
\hline \multirow[t]{3}{*}{ Age, years } & Mean \pm SD & $25.0 \pm 2.9$ & $33.8 \pm 6.2$ & $28.2 \pm 6.7$ & $28.0 \pm 6.7$ & $30.7 \pm 6.8$ & $31.1 \pm 7.6$ \\
\hline & Median & 24.5 & 34.0 & 27.5 & 27.0 & 29.0 & 30.0 \\
\hline & Range & $21-30$ & $22-45$ & $22-44$ & $22-41$ & $23-44$ & $22-44$ \\
\hline \multirow[t]{2}{*}{ Sex M/F } & $(N, \%)$ & M: $5(62.5 \%)$ & M: $5(50.0 \%)$ & M: $8(80.0 \%)$ & M: $7(63.6 \%)$ & M: $8(53.3 \%)$ & M: $11(73.3 \%)$ \\
\hline & & F: $3(37.5 \%)$ & F: $5(50.0 \%)$ & F: $2(20.0 \%)$ & F: $4(36.4 \%)$ & F: $7(46.7 \%)$ & F: $4(26.7 \%)$ \\
\hline \multicolumn{8}{|l|}{ Ethnicity } \\
\hline Caucasian & & $8(100.0 \%)$ & $10(100.0 \%)$ & $10(100.0 \%)$ & $11(100.0 \%)$ & $15(100.0 \%)$ & $15(100.0 \%)$ \\
\hline
\end{tabular}

$B I D$ twice daily; $O D$ once daily; $T I D$ three times daily

${ }^{a}$ Data shown for the efficacy sample (excluding subjects who had protocol deviations)

${ }^{b}$ Data shown for the safety analysis set (all subjects who received at least one dose of study treatment)

Table 3 Mean $( \pm \mathrm{SD})$ spore forms count, AUC for each formulation

\begin{tabular}{|c|c|c|c|}
\hline Study name & Oral formulation & Name & $\begin{array}{l}\text { Mean ( } \pm \mathrm{SD} \text { ) spore forms } \\
\text { count (millions), } \mathrm{AUC}_{0-t}\end{array}$ \\
\hline \multirow[t]{2}{*}{2012 EGKINETIC4 } & Vial $4 \times 10^{9} \mathrm{OD}$ & E4 OD & $213.8 \pm 60.2$ \\
\hline & Vial $2 \times 10^{9} \mathrm{BID}$ & E2 BID & $270.7 \pm 147.7$ \\
\hline \multirow[t]{2}{*}{2012 EGKINETIC6 } & Powder $6 \times 10^{9}$ OD & ES6 OD & $319.0 \pm 221.1$ \\
\hline & Capsule $2 \times 10^{9} \mathrm{TID}$ & EC2 TID & $312.7 \pm 218.0$ \\
\hline \multirow[t]{2}{*}{2016 EGKINETIC6OP } & Sachet $6 \times 10^{9}$ OD & E6 OD & $212.6 \pm 118.0$ \\
\hline & Powder $6 \times 10^{9}$ OD & ES6 OD & $293.2 \pm 247.2$ \\
\hline
\end{tabular}

Spore count in millions; AUC is per hour

$A U C$ area under the curve; $B I D$ twice daily; $O D$ once daily; $T I D$ three times daily 



Fig. 3 Mean spore forms count (after log transformation) over 18 days after Enterogermina treatment. a 2012 EGKINETIC4, b 2012 EGKINETIC6, c 2016 EGKINETIC6OP

mean after logarithmic transformation is presented in Fig. 3b. The mean ( \pm SD) absolute vegetative (total) forms count (in millions) expressed as AUC was $293.7 \pm 193.0$ with EC2 TID and $303.8 \pm 209.3$ with ES6 OD.

\subsubsection{EGKINETIC6OP}

The mean ( \pm SD) absolute spore forms count (in millions) expressed as AUC per hour was $212.6 \pm 118.0$ with E6 OD and $293.2 \pm 247.2$ with ES6 OD (Table 3). The AUC mean after logarithmic transformation is presented in Fig. 3c. The mean $\pm \mathrm{SD}$ values of log-transformed $C_{\max }$ were similar with the two formulations- $6.70 \pm 0.24$ for E6 OD and 6.78 $\pm 0.44 \mathrm{~h}$ for E6S OD. The mean $\pm \mathrm{SD}$ values of $T_{\max }$ were similar with the two formulations $-42.2 \pm 22.5 \mathrm{~h}$ for E6 OD and $46.0 \pm 25.6 \mathrm{~h}$ for E6S OD.

A superimposable AUC and daily curve profile of spore forms was observed with the two formulations in each study up to the 8th day post dose.

\subsection{Presence/Persistence Analysis}

\subsubsection{EGKINETIC4}

Faecal B. clausii spore counts (in millions) had reduced by $50 \%$ (median presence/persistence) after 7.95 days; 95\% CI 6.00-8.00 with E2 BID and 8.40 days; $95 \%$ CI 6.00-9.40 with E4 OD. There were no differences between the two formulations in the presence/persistence distribution function of spores (Fig. 4a).

\subsubsection{EGKINETIC6}

The median presence/persistence was 9.10 days; $95 \%$ CI 6.10-10.50 with EC2 TID and 8.20 days; $95 \%$ CI $6.50-11.50$ with ES6 OD. There were no differences between the two formulations in the presence/persistence distribution function of spores (Fig. 4b).

\subsubsection{EGKINETIC6OP}

The median presence/persistence was 11.0 days; $95 \%$ CI 8.0-13.0 days with $\mathrm{R} \rightarrow \mathrm{T}$ and 10.0 days; $95 \%$ CI $6.0-15.0$ days with $\mathrm{T} \rightarrow \mathrm{R}$. There were no differences between the two formulations in the presence/persistence distribution function of spores (Fig. 4c).

In both treatments periods for each study, the presence/ persistence distribution function was comparable between the two studied formulations and the Kaplan-Meier curves provided evidence of the progressive drop of faeces from Day 8 onwards.

\subsection{Adverse Events}

TEAEs by MedDRA SOC are shown in Table 4 (see Table S1 for TEAE MedDRA preferred terms). As there were no treatment-related adverse events in any subject, no serious TEAEs and none of the TEAEs led to premature study discontinuation, all formulations were therefore considered well-tolerated. In addition, TEAEs showed no clear time relationship with study treatment, were of mild or moderate intensity and resolved at follow-up. 



Fig. 4 Kaplan-Meier curves showing faecal Bacillus clausii counts a 2012 EGKINETIC4, b 2012 EGKINETIC6, c 2016 EGKINETIC6OP

\subsection{Post Hoc Analyses (Variability)}

A post hoc analysis was undertaken to estimate the SD and coefficient of variation within each $B$. clausii study (Table S2). These results show a high variability of 21-61.6\% for AUC spore counts (2012 EGKINETIC4 E2 BID vs E4 OD, SD within 0.21, coefficient of variation 21.15; 2012 EGKINETIC6 E2 TID vs E6 OD, SD within 0.57 , coefficient of variation $61.60 ; 2016$ EGKINETIC6OP, SD within 0.37 , coefficient of variation 38.70 ). The variability ranged from $23-61.9 \%$ for AUC vegetative counts and was $35 \%$ for AUC $C_{\text {max }}$.

\section{Discussion}

Enterogermina products have been available on the market for several years as vials of oral suspension and hard gelatine capsules both containing 2 billion spores of $B$. clausii taken three times daily. More recent formulations include vials containing $4 \times 10^{9} \mathrm{~B}$. clausii spores and powder sachets of 6 $\times 10^{9} \mathrm{~B}$. clausii spores for oral suspension, both suitable for once-daily administration. In comparison to three times daily dosing, these formulations may lead to better compliance and adherence to therapy [14]. Evidence in the literature suggests that differences in delivery method and frequency of administration of probiotics can impact the effectiveness and are recognised by patients as important factors [19, 20]. Availability of once-daily dose formulations may increase adherence to medication.

This analysis summarises the kinetic profiles of the different formulations of Enterogermina (vial, capsule, oral powder for suspension and oral powder with no need for suspension), from three studies undertaken between 2012 and 2016, and brings new information to an area where the number of bioequivalence studies is small and information on kinetic profiles of probiotics limited. In the three studies presented, the kinetic profiles of the different formulations of Enterogermina were similar, with superimposable AUC and daily curve profiles of spore forms observed with the two formulations in each study up to the 8th day post dose. The presence/persistence profile of B. clausii spores in the intestine of healthy volunteers did not differ between the two formulations within each of the three studies. In terms of adverse events, laboratory parameters and vital signs, Enterogermina formulations were well tolerated across all formulations and studies.

Thus, in addition to describing the kinetic profiles of different Enterogermina formulations, this analysis may indicate possible bioequivalence of these formulations. In the absence of probiotic-specific bioequivalence guidelines or established methodology based on measurement of faecal samples, there is a strong case for adapting the 2010 EMA drug bioequivalence guidelines [21]. The EMA guidelines state that bioequivalence is demonstrated when drugs are "pharmaceutically equivalent or pharmaceutical alternatives and their bioavailabilities (rate and extent) after administration in the same molar dose lie within acceptable predefined limits' [21]. Acceptance ranges for AUC are set to ensure comparable in vivo performance, i.e., similarity in terms of safety and efficacy. They also state that the acceptable predefined limits could be adapted (at least for $\mathrm{T}_{\max }$ ) for high-variability products. The results of our post hoc analysis (Table S1) showed that probiotics may have variability $>30 \%$, which is commonly used as the threshold for high variability. The reasons for the 
Table 4 Treatment-emergent adverse events by system organ class

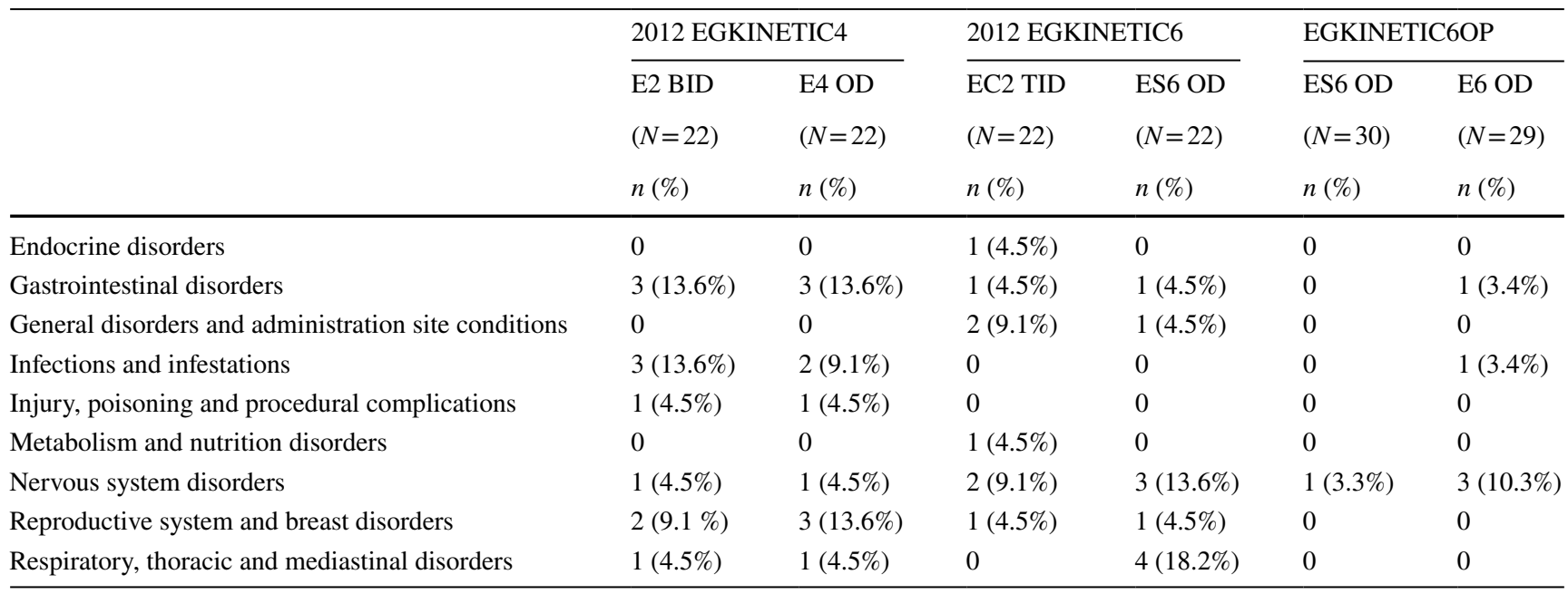

high variability of probiotics may include the nature of the products, the type of sampling used (in this case, faecal samples), and the potential effect of formulation (capsules/vials). It is also important to note that the methods reported here evolved over time; for example, the participants of the 2016 study were hospitalised for the first 3 days for the collection of all evacuations, whereas the participants of the 2012 studies were not hospitalised, and a single daily measurement was used to describe overall CFUs. Bearing in mind the high variability of probiotics, future bioequivalence studies will require a significantly larger sample size, which can present ethical difficulties and may be associated with a high cost.

Here, we have described an initial method for the comparative presence of probiotic spores. An issue inherent to probiotic kinetic analysis is the need for the measurement of faecal samples. A decreased spore count in faeces could be due to spore death, spore germination or both. The inclusion of vegetative forms in the total cell count overcomes this effect to some extent; however, without heat treatment, a heterogeneous mixture of bacterial species can result. These complications can begin to be addressed in subsequent iterations of the methods.

As such, the question for the future is how bioequivalence should be evaluated for probiotics. In particular: (1) For kinetic parameters based on spore counts in faecal samples, should the same range of acceptance be used as defined for drug concentrations in blood samples? (2) Would loosening the acceptance range for all kinetic parameters in order to establish bioequivalence be acceptable (especially in Europe, where requirements to establish bioequivalence of drugs are more stringent compared with other countries worldwide)? (3) In the EMA guidelines, AUC and $T_{\max }$ need to be equivalent to confirm a bioequivalence between products. However, is $T_{\max }$ relevant as a parameter for probiotics, and could bioequivalence be demonstrated based only on the AUC?

\section{Conclusion}

Different formulations of Enterogermina were very similar in terms of kinetic profile within each study. The variety of doses and administration schedules used in these studies may provide additional flexibility to individuals with different lifestyles. Assessing bioequivalence for probiotics may be challenging and is not covered in current guidelines. This study provides initial ideas that may pave way to the development of probiotic-specific guidelines on bioequivalence.

Supplementary Information The online version contains supplementary material available at https://doi.org/10.1007/s13318-021-00676-2.

Acknowledgements The authors would like to thank study subjects, investigators, co-investigators, and the study teams at the participating centres and at Sanofi. Editorial support was provided by Ella Palmer, $\mathrm{PhD}, \mathrm{CMPP}$ of inScience Communications, Springer Healthcare Ltd, UK, and was funded by Sanofi.

\section{Declarations}

Funding Sanofi provided financial support for the conduct of the research and preparation of the article. Sanofi, in collaboration with all authors, was involved in the study design; in the collection, analysis and interpretation of data; in the writing of the report; and in the decision to submit the article.

Conflicts of Interest MP, MCU, PP, BBDF are employees of Sanofi Aventis. PN has undertaken consultancy for Sanofi and attended board meetings supported by Sanofi.

Ethics Approval Approval was obtained from the local ethics committee prior to the conduct of any study-related procedures. The protocol 
complied with recommendations of the 18th World Health Congress (Helsinki, 1964) and all applicable amendments. The protocol also complied with the laws and regulations, as well as any applicable guidelines, of the country where the study was conducted.

Consent to participate Not applicable as this section relates to case reports/case series.

Consent for publication All authors agreed to submit this manuscript to European Journal of Drug Metabolism and Pharmacokinetics.

Availability of Data and Material Qualified researchers may request access to subject level data and related study documents including the clinical study report, study protocol with any amendments, blank case report form, statistical analysis plan, and dataset specifications. Patient level data will be anonymized, and study documents will be redacted to protect the privacy of our trial participants. Further details on Sanofi's data sharing criteria, eligible studies, and process for requesting access can be found at: https://www.clinicalstudydatarequest.com/.

Code Availability Not applicable.

Open Access This article is licensed under a Creative Commons Attribution-NonCommercial 4.0 International License, which permits any non-commercial use, sharing, adaptation, distribution and reproduction in any medium or format, as long as you give appropriate credit to the original author(s) and the source, provide a link to the Creative Commons licence, and indicate if changes were made. The images or other third party material in this article are included in the article's Creative Commons licence, unless indicated otherwise in a credit line to the material. If material is not included in the article's Creative Commons licence and your intended use is not permitted by statutory regulation or exceeds the permitted use, you will need to obtain permission directly from the copyright holder. To view a copy of this licence, visit http://creativecommons.org/licenses/by-nc/4.0/.

\section{References}

1. Group JFWW. Joint FAO/WHO Working Group Report on Drafting Guidelines for the Evaluation of Probiotics in Food. London, Ontario, Canada, April 30 and May 1. 2002. https://www.who.int/ foodsafety/fs_management/en/probiotic_guidelines.pdf. Accessed 1 Apr 2020.

2. Ministero della S. Direzione Generale per L'igiene E La Sicurezza Degli Alimenti E La Nutrizione-Ufficio 4 Linee Guida Su Probiotici E Prebiotici Revision March. 2018. http://www.salute.gov. it/imgs/C_17_pubblicazioni_1016_allegato.pdf. Accessed 1 Apr 2020.

3. Bell V, Ferrão J, Pimentel L, Pintado M, Fernandes T. One health, fermented foods, and gut microbiota. Foods. 2018. https://doi. org/10.3390/foods7120195.

4. Angioi A, Zanetti S, Sanna A, Delogu G, Fadda G. Adhesiveness of Bacillus subtilis strains to epithelial cells cultured in vitro. Microb Ecol Health Dis. 1995;8(2):71-7. https://doi. org/10.3109/08910609509141385.

5. Cenci G, Trotta F, Caldini G. Tolerance to challenges miming gastrointestinal transit by spores and vegetative cells of Bacillus clausii. J Appl Microbiol. 2006;101(6):1208-15. https://doi.org/ 10.1111/j.1365-2672.2006.03042.x.

6. Ciffo F, Da Carro C, Giovannetti M. Gastric resistance of Bacillus subtilis spores used in oral bacteriotherapy: in vitro studies. Farmaci e Terapia. 1987;3:163-9.
7. Ciffo F. Determination of the spectrum of antibiotic resistance of the "Bacillus subtilis" strains of Enterogermina. Chemioterapia. 1984;3(1):45-52.

8. Mazza P. The use of Bacillus subtilis as an antidiarrhoeal microorganism. Boll Chim Farm. 1994;133(1):3-18.

9. Sanofi. Enterogermina. Summary of Product Characteristics. 2019. https://globalmicrobiotasummit.com/wp-content/uploa ds/2019/03/SHG_BO_SmPC_14032019_004.pdf. Accessed 1 Apr 2020.

10. Besana R, Daroda C, Losa P. Trattamento delle forme diarroiche di origine alimentare o batterica nella prima infanzia con spore di Bacillus subtilis (in Italian). Aggiorn Pediatr. 1980;XXXI(5-6).

11. Puddu M, Schirru A, Di Fazio A, Artuso A, Bellioni A, Strappini M, Businco L. Esperienze cliniche con il Bacillus subtilis in bambini trattati con antibiotici (in Italian). Ped Intern. 1980;6(1-6):6.

12. Benoni G, Marcer V, Cuzzolin L, Raimo F. Antibiotic administration and oral bacterial therapy in infants. Chemioterapia. 1984;3(5):291-4.

13. Nista EC, Candelli M, Cremonini F, Cazzato IA, Zocco MA, Franceschi F, Cammarota G, Gasbarrini G, Gasbarrini A. Bacillus clausii therapy to reduce side-effects of anti-Helicobacter pylori treatment: randomized, double-blind, placebo controlled trial. Aliment Pharmacol Ther. 2004;20(10):1181-8. https://doi.org/10.11 11/j.1365-2036.2004.02274.x.

14. Richter A, Anton SF, Koch P, Dennett SL. The impact of reducing dose frequency on health outcomes. Clin Ther. 2003;25(8):230735. https://doi.org/10.1016/s0149-2918(03)80222-9.

15. Bello FD, Walter J, Hertel C, Hammes WP. In vitro study of prebiotic properties of levan-type exopolysaccharides from Lactobacilli and non-digestible carbohydrates using denaturing gradient gel electrophoresis. Syst Appl Microbiol. 2001;24(2):232-7. https:// doi.org/10.1078/0723-2020-00033.

16. Walter J, Tannock GW, Tilsala-Timisjarvi A, Rodtong S, Loach DM, Munro K, Alatossava T. Detection and identification of gastrointestinal Lactobacillus species by using denaturing gradient gel electrophoresis and species-specific PCR primers. Appl Environ Microbiol. 2000;66(1):297-303. https://doi.org/10.1128/ aem.66.1.297-303.2000.

17. Hanifi A, Culpepper T, Mai V, Anand A, Ford AL, Ukhanova M, Christman M, Tompkins TA, Dahl WJ. Evaluation of Bacillus subtilis $\mathrm{R} 0179$ on gastrointestinal viability and general wellness: a randomised, double-blind, placebo-controlled trial in healthy adults. Benef Microbes. 2015;6(1):19-27. https://doi.org/10.3920/ bm2014.0031.

18. Hong HA, le Duc H, Cutting SM. The use of bacterial spore formers as probiotics. FEMS Microbiol Rev. 2005;29(4):813-35. https ://doi.org/10.1016/j.femsre.2004.12.001.

19. Govender M, Choonara YE, Kumar P, du Toit LC, van Vuuren $\mathrm{S}$, Pillay V. A review of the advancements in probiotic delivery: conventional vs. non-conventional formulations for intestinal flora supplementation. AAPS Pharm Sci Tech. 2013;15(1):29-43. https ://doi.org/10.1208/s12249-013-0027-1.

20. Nguyen M, Ferge KK, Vaughn AR, Burney W, Teng LH, Pan A, Nguyen V, Sivamani RK. Probiotic supplementation and food intake and knowledge among patients and consumers. Probiotics Antimicrob Prot. 2019. https://doi.org/10.1007/s12602-019-09602 -0 .

21. European Medicines Agency New EMA Guideline on the Investigation of Bioequivalence. 2020. https://www.ema.europa.eu/en/ documents/scientific-guideline/guideline-investigation-bioequival ence-rev1_en.pdf. Accessed 1 July 2020. 


\section{Authors and Affiliations}

\section{Pierluigi Navarra ${ }^{1}$. Stefano Milleri' ${ }^{2}$ Marcos Perez III $^{3}$. Maria Chiara Uboldi ${ }^{4}$ Paolo Pellegrino ${ }^{4}$.} Beatrice Bois De Fer ${ }^{5} \cdot$ Lorenzo Morelli6 $^{6}$

1 Section of Pharmacology, Department of Healthcare surveillance and Bioethics, Catholic University Medical School, Catholic University of the Sacred Heart, Milan, Italy

2 Centro Ricerche Cliniche di Verona srl, Verona, Italy

3 Global Medical, Consumer Healthcare, Sanofi-Aventis Deutschland GmbH, Frankfurt, Germany

4 CHC Medical Department, Sanofi, Italy
5 Sanofi Consumer Health Care Analytical and Scientific Platforms, Sanofi Clinical Sciences and Operations, Paris, France

6 DiSTAS, Università Cattolica del Sacro Cuore, Piacenza, CR, Italy 